\title{
马
}

JURNAL

Riset Akuntansi dan Keuangan Indonesia

URL : http://journals.ums.ac.id/index.php/reaksi/index

\section{Study on The Wandering}

Weekday Effect In The

\section{Indonesian Capital Market}

Based On Trend Moderation

\section{Effect}

\section{Usman Arief}

Management Department, Faculty of Economics and Business, Universitas Gadjah Mada

Email: usman.arief@ugm.ac.id

\section{Keywords:}

asset pricing, anomaly, finance, capital market

\section{ABSTRACT}

This study investigates a wandering weekday effect, an assumption anomaly from fixed weekday effect to changes over time, under the moderation effect of market trend. We employ daily price data from the Jakarta Stock Exchange (JKSE) from 2000 to 2019. This study reveals that the fixed weekday effect has diminished when we introduced a market trend. Using robustness of distribution error, our further studies find that there is a negative wandering Monday effect when the market is falling. The findings provide a crucial contribution to market efficiency and help to reconcile mixed findings in previous studies 
Zhang, Lai, and Lin (2017) internationally

The weekday effect anomaly is one of the wellknown anomalies in the stream research of asset pricing and many previous studies that discuss this topic. This anomaly is often associated with seasonality effects that exist in the capital market in creating a seasonal pattern of stock return such as returns are higher on some days of the week than others, or at some times of the months, and some months of the year.

The efficient market hypothesis (EMH) from Fama (1970) suggests that stock prices reflect all available information. Therefore, seasonality effect challenges EMH since investors can curb high returns simply by knowing the day of the week pattern in capital markets. As a consequence, many previous studies reveal the weekday effect using the sample from global stock markets for the international evidence due to the simplicity of the pattern and easier to recognized compared to other seasonality anomalies (see Kiymaz and Berument (2003)).

The traditional weekday effect states that Monday's return is on average lower than other days. Research from Kelly (1930) argued that the US capital market's return is lower on Monday and then slowly rises until it reaches its highest point on Friday. Other studies that support previous studies are from Cross (1973); French (1980), Keim (1983) and Keim and Stambaugh (1984) which shows that returns on the US capital market and several other countries are relatively lower on Monday.

Other studies link the phenomenon of the weekday effect with the investor psychology hypothesis. Birru (2018) argued that investor psychological factors and moods tend to be more dominant in making decisions for buying or selling stocks. Investors tend to have a high mood on Friday and then fall on Monday, causing a negative return on Monday and the highest on Friday. Birru's findings are supported by findings from Chiah and Zhong (2019) using data from 24 countries, they empirically find that negative returns on Monday and positive returns on Friday are a reflection of investors' pessimism and optimism in assessing the company's future prospects. In addition, they found that negative returns were not only found on Monday but varied in a some days. examined the anomaly weekday effect in a rolling sample and found that the lowest return was on Wednesday for Europian capital markets, and Friday for the stock markets in Hong Kong and Argentina. Recent findings from Boubaker et al. (2017) using data from 51 stock market indices around the world found that the day-of-week effect appeared not only on Monday and Friday but varied for the whole day. The findings support the previous papers that the weekday effect is not only occurs on Monday.

The divergency results from previous research articles is probably due to the poor inferencial econometrics process. Boubaker et al. (2017) explain that there is a potential fragility of the inference process of an econometrics model to test the anomaly weekday effect which results in spurious goodness-of-fit. This possibility causes the previous studies to have mixed results without a clear conclusion or often referred to as an artifact of econometrics fragility. Hansen et al. (2005) argue that the theoretical explanation of this weekday effect will not reach a solid conclusion and continue to develop because there is not one strong conclusion of empirical results yet.

Another possible explanation for the day-ofthe-week effect is that it is flux rather than fixed over time so that the traditional econometric model cannot capture the effect. Seasonal effects on the stock market may have evolved to become no longer fixed through time but instead developed into flux. Research from Mehdian and Perry (2001) find a significant negative return in the period before 1987 and turned positive after 1987. General points that could be obtained is seasonality evolves and may manifest into a certain point of time and it causes flux. However, the fixed weekday effect assumes that the seasonal anomaly should be steady over time rather than a continuous state or flux, which may be difficult to grasp the changing characteristics of return. Therefore, the main motivation of this research is to test beyond the anomaly weekday effect which is fixed and steady overtime to dynamic over time which is called the wandering weekday effect (see Doyle and Chen (2009)).

Different from previous studies from Doyle and Chen (2009) to test the wandering weekday effect using interaction between weekday and time, this paper investigates the following novelties: 1 ) we 
divide returns on the Indonesian Capital Market (JCI) into two states: high-frequency volatility state and low-frequency volatility state. Each state manifests two prominent market trends (rising and falling trend). 2) we take the market trend as a moderator to measure the wandering weekday effect under different frequencies. 3) to improve the consistency of the results, we perform robustness of the week-day effects to error distribution assumptions for the mean and variance of the process with the AR-GARCH (p, q) model. We argue that the sensitivity of seasonalities in the capital market is determined by the assumption of an error distribution when market conditions experience rising and falling.

We use the daily dataset from the Indonesian Capital Market (JCI) from 2000 to 2019. The layout of this paper is as follows. Section 2 literature review. Section 3 describes the data and methodology. Section 4 presents the results and section 5 is the discussion.

\section{LITERATURE REVIEW}

\section{Steady Seasonals or Flux Through Time}

Before examining the phenomenon of the wandering effect, we will explain the basic assumption from previous research that seasonality is fixed with time. This assumption is derived from market conditions that have negative or positive persistent returns on certain days caused by news releases, changing macroeconomic conditions, and the mood conditions of traders. Some classic studies from Cross (1973) found that returns on Friday were higher than returns on Monday for the period 1953 and 1970. Similar results were reported by French (1980), Gibbons and Hess (1981) and Keim and Stambaugh (1984) for various portfolios return. Their results confirm that the weekday effect occurs in the US in a fixed period. Also this phenomenon occurs in other countries in the world as in research from Jeffrey and Westerfield (1985) empirically found that the stock market in Australia, Canada, Japan and the UK experienced negative persistence of returns on Tuesday. The evidence is supported by another study from Solnik and Bousquet (1990) that the French stock market had a negative persistent return on Tuesday.

In contrast, the seasonality effect probably has the potentiality to evolve from fixed to flux as in the findings from Mehdian and Perry (2001) found the negative return on Monday before 1987 and the negative Monday return turned into positive return after 1987. Doyle and Chen (2009) find that wandering effects are more significant compared to the weekday effect for 13 major stock markets around the world. Boubaker et al. (2017) use several variations of the error distribution to perform robustness check to test both weekend and wandering effect using 51 stock market data worldwide. They find that the wandering effect tends to be stronger and more sensitive in the selection of error distribution than the weekend effect.

Based on the comparison of several classical studies and recent research findings regarding the seasonal effect, we hypothesize that the current business environment conditions are different from 4 decades ago where classical papers from 1970 to 1990 revealed the fixed weekday effect but some recent studies show that the weekday effect is longer fixed. Some factors cause this changing including; the changes the day of announcement of key economic indicators (macro announcements) on non-Monday (see Steeley (2001) and Doyle and Chen (2009), other factors such as the availability of electronic tradings make investor easier to trade anytime. Traders are aware to use oftenly the simple strategy "Buy on Monday and Sell on Friday" hence the weekend effect has disappeared and create a new seasonality effect. These factors contribute to change the fixed findings of the weekday effect to be a continually adjusting through time.

\section{RESEARCH METHODS}

\section{Data and Model Econometrics}

We use daily stock price data from the Indonesia Stock Exchange (JCI) from January 4, 2000 to December 30, 2019. Data are collected from Datastream. We use the continously compounded method to calculate daily returns in the following way:

$$
r_{t}=100 \times \ln P_{t}-\ln P_{t-1}
$$

Where Pt is the closing stock price at time t. This study seperate the market returns into two states : high-frequency volatility and low-frequency volatility as in Eq.(2). 
$R_{t}=$ high-frequency volatility state $R_{t}$, if

$$
\left|R_{t}-\bar{R}\right| \geq \sum_{t=1}^{n}\left|R_{t}-\bar{R}\right| / n
$$

low-frequency volatility state $R_{t}$, if

$\left|R_{t}-\bar{R}\right|<\sum_{I=1}^{n}\left|R_{t}-\bar{R}\right| / n$

The investors' attitude and psychology to risk can depart significantly from prediction of expected utility from gains and losses associated to risk taking. According to this, we divide the market trend of JCI into rising and falling trend and studied the daily trading decisions driven by investors risk attitudes. Inspired by Zhang et al. (2019), we divide the market trend as in equation (3).

$$
\begin{aligned}
\text { Trend }= & \text { TR, } \mathrm{j}=1\left(\operatorname{Tup}=\mathrm{P}_{\mathrm{t}}-\mathrm{P}_{\mathrm{t}-1}, \text { if } \mathrm{P}_{\mathrm{t}}-\mathrm{P}_{\mathrm{t}-1}\right. \\
& >0 \text { and } 0 \text { otherwise } \\
\text { TF } j=1 & \left(\text { Tup }=P_{t}-P_{t-1}, \text { if } P_{t}-P_{t-1}\right. \\
& >0 \text { and } 0 \text { otherwise }
\end{aligned}
$$

Where TR and TF represents th e rising and falling trend.

This paper employ model from Boubaker et al. (2017) and Zhang, Yun, and Wagan (2019) that includes the AR model in the mean equation, so the mean equation model becomes as follows:

$$
R_{t}=\alpha+\sum_{j=2}^{5} \beta j D a y+\sum_{k=1}^{5} \gamma R_{t-k}+\varepsilon_{t}
$$

$\mathrm{R}_{\mathrm{t}}$ is daily returns at time $\mathrm{t}$, and Monday is the base condition for the first day as a dummy variable. $\gamma$ is the coefficient for the five lag auto-regressive term (AR). We use AR up to 5 lags because the data we use is the daily closing price which allows us to capture the effects of seasonalities on 5 working days a week. To control heteroscedasticity in the data, we employ GARCH $(1,1)$ in $\operatorname{Eq}(5)$. Where $\sigma^{2}$ is the conditional variance.

$$
\sigma^{2}{ }_{\mathrm{t}}=\kappa+\delta \sigma_{\mathrm{t}-1}^{2}+\alpha \varepsilon^{2}{ }_{\mathrm{t}-1}
$$

for depicting the influence of market volatility, the variance is introduced into the mean equation and referring the model of GARCH in Mean in eq (6)

$$
R_{t}=\alpha+\sum_{j=2}^{5} \beta j \text { Day }+\sum_{k=1}^{5} \gamma R_{t-k}+\delta \sigma_{t-1}+\varepsilon_{t}
$$

We identify the pattern of the wandering effect by analyzing the cross-multiplication term of daily dummy variables and market trends in eq (7). Where Day and Trend x Day represent daily returns and daily returns under the moderation effect of market trend respectively. All the testing of fixed weekday as well wandering weekday effect, we employ both mean and variance model sequentially.

$$
\begin{aligned}
R_{t} & =\alpha+\sum_{j=2}^{5} \beta j \text { Day }+\sum_{k=1}^{5} \gamma R_{t-k}+\sum_{j=2}^{5} \\
& +\sum_{k=1}^{2} \theta \text { Trend }_{t-k} x \text { Day }+\delta \sigma_{t-1}+\varepsilon_{t}
\end{aligned}
$$

\section{RESULTS AND DISCUSSION}

\section{Descriptive Statistics}

In this section, kami akan bercerita tentang deskriptive statistics results graphs. Figure 1 shows the volatility of the Indonesia Capital Market (JCI). To reflect the volatility return more accurately, we divide the JCI return into two states following Zhang et al. (2019) including : high-frequency volatility and low-frequency volatility state as is depicted in Figure 2.

Figure 1. Return Volatility

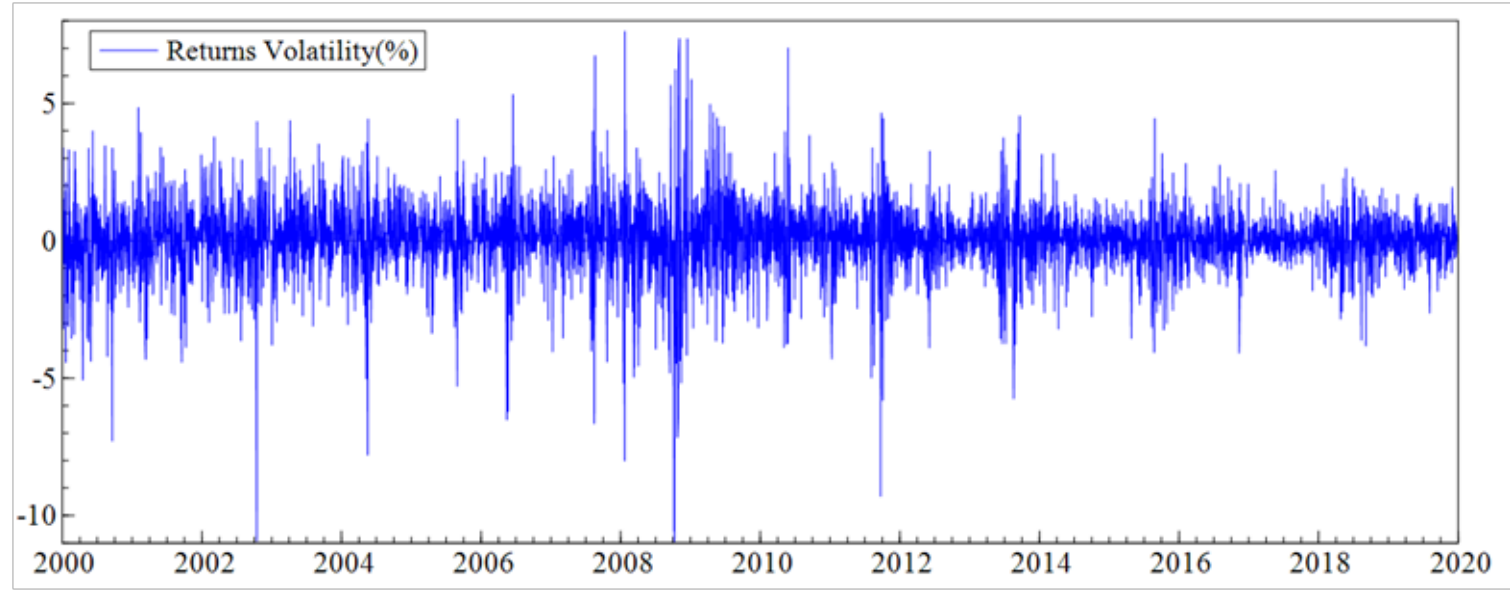


Figure 2 shows 20 years observations period. It is clear that the Indonesian capital market experienced very high volatility in 2002, 2008 when the global financial crisis (GFC) occurred and in 2012. After the 2014 period, the JCI experienced relatively tranquil compared to the previous period.

Figure 2. Two States of Volatility in JCI

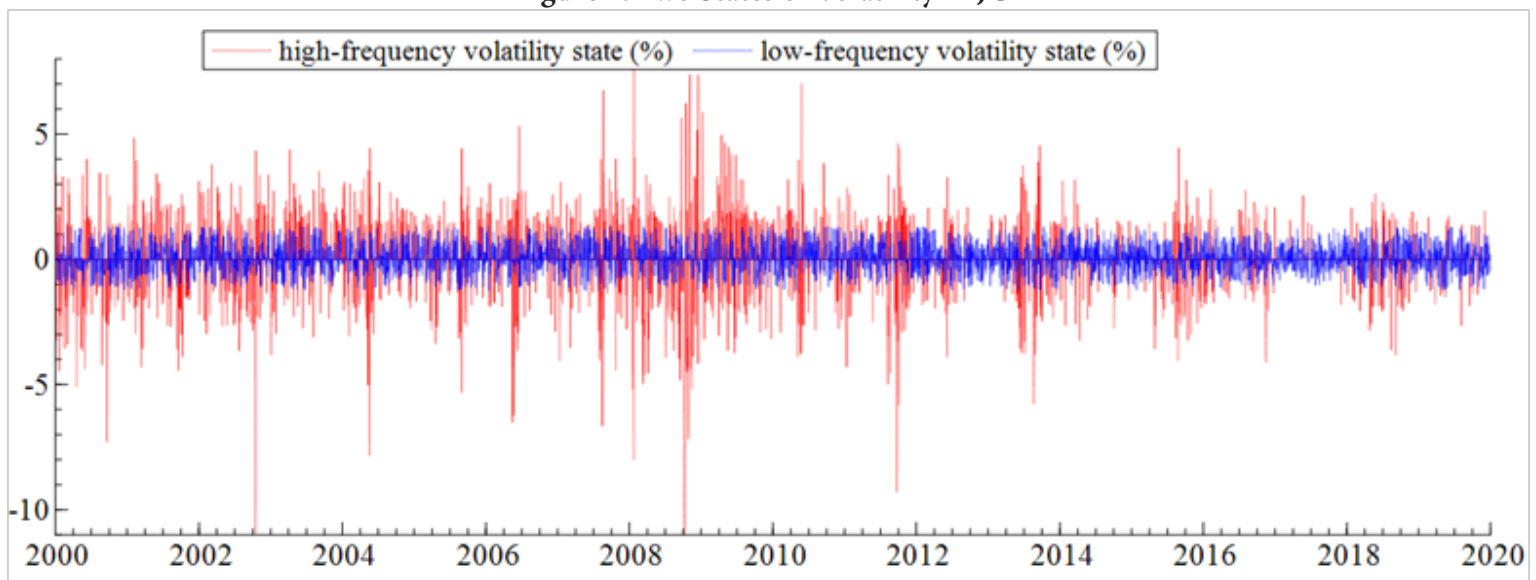

We divide the two states volatility into a rising and falling trend period to see the investor trading patterns and trading decisions when volatility is high (low) and market trends are rising (falling). Figure 3 shows that at the time of the GFC the market trend tended to fall by - $10 \%$ compared to 2012 which only less than $-9 \%$. In constrast, Figure 4 portrays the range of market trends in low- frequency state from $-1 \%$ to $1 \%$. This market trend is relatively stable compared to market trends in Figure 3. To reflect the wandering weekday effect and capture the changing characteristics of market as in figure 3 and figure 4, we take market trend as a moderator in the mean equation of $\mathrm{AR}(5)-\mathrm{GARCH}$ $(1,1)$ model.

Figure 3. Volatility of the JCI returns under the rising and falling trend in high-frequency state.

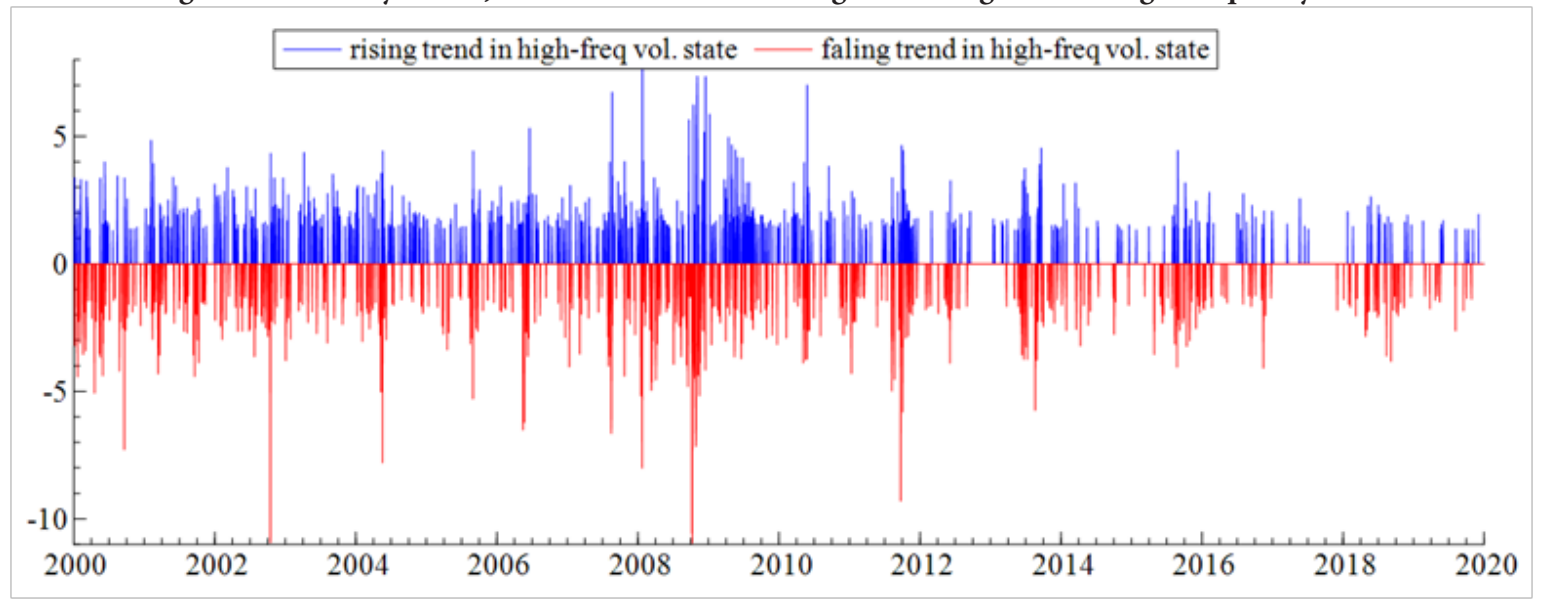


Figure 4. Volatility of the JCI returns under the rising and falling trend in low-frequency state.

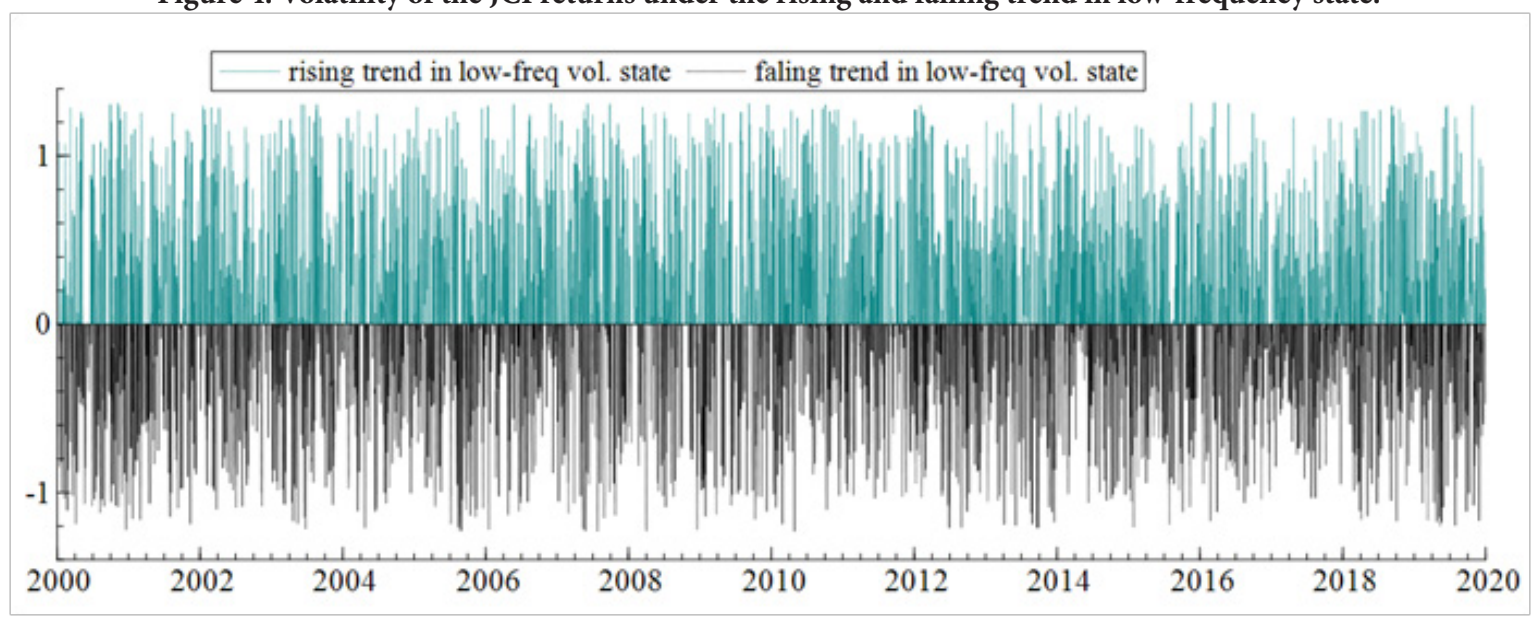

The descriptive statistics of the sample are show in table 1. For total sample and high-frequency volatility state, the highest average returns are on Wednesday and Monday, and the average return on Monday and Friday are said to be the lowest. For the low-frequency volatility state, the highest return are observed on Thursday while the average returns on the rest of the days are relatively the same at about $0,270 \%$. Normally, when we study seasonality using full sample of market indice, we will find the Monday effect. however, our descriptive statistics results indicate that there is a different seasonality pattern when we divide the market into two states.

Table.1 Descriptive Statistics

\begin{tabular}{lcccc}
\hline \multicolumn{1}{c}{ Panel A Daily return : 2000.01.01 - 2019.12.31 } & Mean & Std.Dev & Min & Max \\
\hline Monday & -0.132 & 1.487 & -10.934 & 7.362 \\
Tuesday & 0.042 & 1.195 & -8.010 & 6.238 \\
Wednesday & 0.138 & 1.283 & -10.954 & 7.623 \\
Thursday & 0.046 & 1.232 & -9.300 & 5.268 \\
Friday & 0.120 & 1.133 & -7.155 & 6.819 \\
\hline Panel B : high-frequency volatility state & & & & \\
\hline Monday & 1.964 & 7.587 & 0.000 & 120.481 \\
Tuesday & 1.142 & 3.603 & 0.000 & 64.848 \\
Wednesday & 1.365 & 5.398 & 0.000 & 120.928 \\
Thursday & 1.255 & 4.265 & 0.000 & 87.281 \\
Friday & 1.013 & 3.471 & 0.000 & 51.814 \\
\hline Panel C : low-frequency volatility state & & & & \\
\hline Monday & 0.276 & 0.394 & 0.000 & 1.624 \\
Tuesday & 0.285 & 0.398 & 0.000 & 1.617 \\
Wednesday & 0.290 & 0.411 & 0.000 & 1.624 \\
Thursday & 0.262 & 0.377 & 0.000 & 1.623 \\
Friday & 0.276 & 0.402 & 0.000 & 1.618 \\
\hline
\end{tabular}

\section{Fixed Weekday Effect Estimation Results}

Empirical results recorded in Table 2 show that in high-frequency volatility state, there is a negative fixed Monday effect under the normal and student-t distribution. Additional model AR(5)-
GARCH (1,1)-M introduced market variance in the mean process to control market volatility. However, the model $\operatorname{AR}(5)-\operatorname{GARCH}(1,1)$ with student- $t$ distribution display a better fitting performance under the AIC minimum principle. 
Table 3 show the AR(5)-GARCH $(1,1)$ model reflects a significant positive Tuesday to Friday effect under two distribution assumption, normal and student- $t$, while under the model AR(5) - GARCH $(1,1)-\mathrm{M}$ does not show any significant value in each day. This indicates the fixed Monday effect under the market variance as a control does not show the existence of seasonality effect. However, under the AIC rule, the best fitting model is AR(5)$\operatorname{GARCH}(1,1)$ under the normal distribution. The model is effective in depicting return distribution with the absence of fat-tail returns. Therefore, from the model, we can conclude that low-frequency volatility states experience a positive seasonalities effect for all days accept Monday.

However, the assumption behind the fixed weekday effect insist seasonality should become steady, that means the volatility of return is stable over time. This assumption is contrary to the changing stylized facts of returns portrayed in figure 1 and figure 2, to let alone reflect the return volatility under different market trend accurately. To rectify the defects, a wandering weekday effect with moderation of market trends under high and low-frequency state is tested. 


\section{Wandering Weekday Effect Estimation Results}

The empirical results for wandering weekday

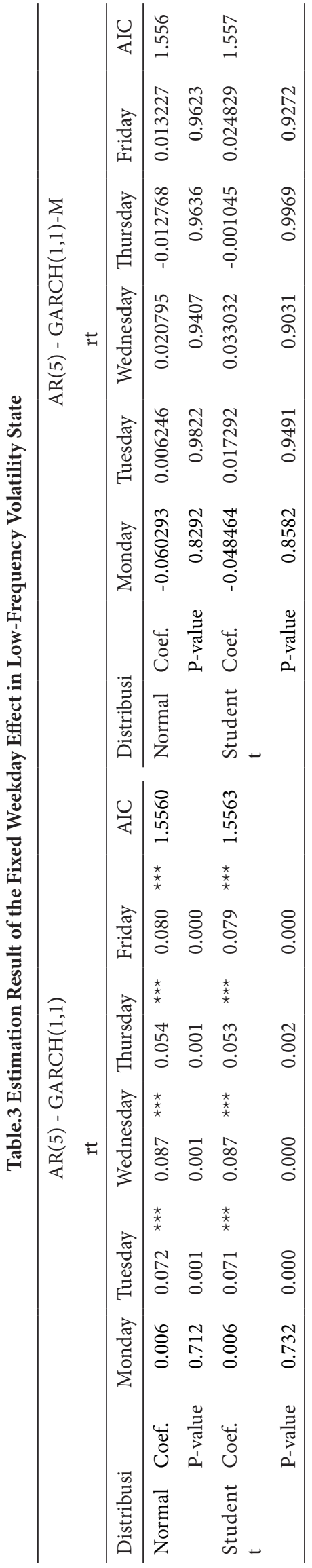
effect in high-frequency volatility state depicted in Table 4. According to the table, we empirically find that there is no fixed seasonality effect under the student- $t$ distribution as the best fitting distribution to capture fat-tail returns. However, under the moderation of market trends, there is a negative significant wandering Monday effect when the market falling. Under normal distribution, the model AR(5)-GARCH $(1,1)$ does not present any pattern of wandering weekday effect, while ,under the student-t distribution, the model displays a negative Monday effect when the market falling. More importantly, when we control the market trend, the fixed weekday effect diminish in all days. It implies that market trends are the important variables to control the seasonality effect and must be included in the model to prevent the spurious estimation results.

Table.4 Estimation Result of the Wandering Weekday Effect in High-Frequency Volatility State

\begin{tabular}{lrrrr}
\hline & \multicolumn{2}{c}{ AR(5) - } & \multicolumn{2}{c}{ AR(5) - } \\
& \multicolumn{2}{c}{ GARCH(1,1) } & \multicolumn{2}{c}{ GARCH(1,1)-M } \\
& Normal & Student-t & Normal & Student- \\
\hline Monday & 0.000 & 0.000 & -0.056 & -0.001 \\
Tuesday & 0.000 & 0.000 & -0.051 & -0.029 \\
Wednesday & 0.000 & 0.000 & -0.038 & -0.050 \\
Thursday & 0.000 & 0.000 & -0.047 & -0.036 \\
Friday & 0.000 & 0.000 & -0.047 & -0.051 \\
TR* & & & & \\
Monday & 0.305 & 0.235 & 0.313 & -0.028 \\
TR* & & & & \\
Tuesday & 0.236 & 0.180 & 0.239 & 0.000 \\
TR* & & & & \\
Wednesday & 0.290 & 0.231 & 0.278 & 0.021 \\
TR & & & & \\
Thursday & 0.291 & 0.212 & 0.289 & 0.006 \\
TR*Friday & 0.277 & 0.191 & 0.275 & 0.022 \\
TF*Monday & $-0.473^{* *}$ & $-0.348^{* * *}$ & -0.465 & $-0.028^{* * *}$ \\
TF*Tuesday & -0.292 & -0.253 & -0.292 & 0.000 \\
TF* & & & & \\
Wednesday & -0.322 & -0.243 & -0.335 & 0.021 \\
TF* & & & & \\
Thursday & -0.361 & -0.257 & -0.365 & 0.006 \\
TF*Friday & -0.287 & -0.208 & -0.287 & 0.022 \\
AIC & 2.602 & 2.268 & 2.602 & -2.721 \\
Adj.R- & & & & \\
Squared & 0.160 & 0.131 & 0.158 & 0.169 \\
\hline
\end{tabular}


When the market in low-frequency volatility state, as in table 5, the results suggest that based on AIC result, the best model is AR(5)-GARCH(1,1)-M using student $\mathrm{t}$-distribution. We empirically find that there is no wandering effect in low-frequency volatility state.

Table.5 Estimation Result of the Wandering Weekday Effect in Low-Frequency Volatility State

\begin{tabular}{|c|c|c|c|c|}
\hline & \multicolumn{2}{|c|}{$\begin{array}{c}\text { AR(5) - } \\
\text { GARCH }(1,1)\end{array}$} & \multicolumn{2}{|c|}{$\begin{array}{c}\operatorname{AR}(5)- \\
\operatorname{GARCH}(1,1)-M\end{array}$} \\
\hline & Normal & Student- $\mathrm{t}$ & Normal & Student- $\mathrm{t}$ \\
\hline Monday & 0.000 & 0.000 & -0.084 & -0.084 \\
\hline Tuesday & 0.000 & 0.000 & -0.082 & -0.082 \\
\hline Wednesday & 0.000 & 0.000 & -0.080 & -0.080 \\
\hline Thursday & 0.000 & 0.000 & -0.083 & -0.083 \\
\hline Friday & 0.000 & 0.000 & -0.084 & -0.084 \\
\hline $\mathrm{TR}^{\star}$ Monday & 0.414 & $0.416^{* * *}$ & 0.414 & 0.414 \\
\hline TR ${ }^{\star}$ Tuesday & 0.444 & $0.444^{\star * *}$ & 0.441 & 0.441 \\
\hline \multicolumn{5}{|l|}{$\mathrm{TR}^{\star}$} \\
\hline Wednesday & 0.425 & $0.421^{\star \star *}$ & 0.421 & 0.421 \\
\hline $\mathrm{TR}^{\star}$ Thursday & 0.413 & $0.412^{\star * \star}$ & 0.411 & 0.411 \\
\hline TRFriday & 0.426 & 0.429 & 0.425 & 0.425 \\
\hline $\mathrm{TF}^{\star}$ Monday & -0.378 & $-0.373^{\star * *}$ & -0.379 & -0.379 \\
\hline TF*Tuesday & -0.369 & $-0.368^{* * *}$ & -0.372 & -0.372 \\
\hline \multicolumn{5}{|l|}{$\mathrm{TF}^{*}$} \\
\hline Wednesday & -0.385 & $-0.384^{\star * *}$ & -0.388 & -0.388 \\
\hline TF*Thursday & -0.370 & $-0.369^{\star *}$ & -0.372 & -0.372 \\
\hline TF*Friday & -0.386 & -0.383 & -0.387 & -0.387 \\
\hline AIC & 0.798 & 1.177 & 0.778 & 0.759 \\
\hline $\begin{array}{l}\text { Adj.R- } \\
\text { Squared }\end{array}$ & 0.531 & 0.530 & 0.531 & 0.532 \\
\hline
\end{tabular}

\section{Discussion Fixed Weekday and Wandering Weekday Effect}

This study makes the case that dengan menganalisa day seasonals time-varying rather than fixed in time reveals new sources of market inefficiency that standard perspective has been ignored. When we analyzing for fixed weekday effect, we find a significant negative Monday effect. However, when we introduce the market trend as moderator variable, the fixed weekday effect loses in statistical power over more precise test. We show that wandering effect is better to explain the variability of return in high and low-frequency state in both rising or falling market trends

Another point, Akaike Information Criterion (AIC) is a standard rule to measure the perfomance of econometrics model. We argue that AIC value of wandering weekday effect in high and lowfrequency state (Table 4 and Table 5) are smaller than that of the model of fixed weekday effect which is depicted in Table 2 and Table 3. Thus, we conclude that wandering effect is more accurate and reliable to describe daily volatility than fixed weekday effect.

A plausible reason for our findings is the investors' psychology in trading decision for different volatility state and market trends. In high-frequency volatility state, when market is rising, the corresponding expected return is higher and investor confidence rises, the investor tend to increase their Friday's holdings which result a substantial increase in earning on Friday. However, investor will take risk hedging transactions and dispose their asset timely for risk aversion on Monday, resulting in a sharp decline of Monday's earning, which is form a negative wandering Monday effect. On the other hand, when the market is falling, the market prospect is not optimistic, and the investors tend to take short sell deals and reduce the market holding asset on Monday which result in a short decline of Monday's return and forming a wandering Monday effect.

Our study is in line with the study from Doyle and Chen (2009) and Boubaker et al. (2017) that suggest the wandering effect is significant to explain the seasonality anomaly while fixed weekday effect has diminished and no longer accurate to explain the seasonality from the major stock markets in the globe.

\section{CONCLUSION}

This research examines the wandering weekday effect in the Indonesian Capital Market (JCI). The general assumption of market inefficiency states that seasonality should fixed rather than flux over time. We challange this general assumption by testing both fixed weekday and wandering effect using market trendas the moderator. The results show that JCI manifest a wandering weekday effect only in high-frequency state, there is a negative wandering Monday effect when market is falling. We also confirm that the wandering weekday effect is very sensitive to the choice of error distribution as the same as with the finding from Boubaker et al. (2017). 
The study of wandering weekday effect under the moderation of rising and falling trends in high and low-frequency state is more reasonable and accurate to detect the volitionally of daily returns. The pattern of wandering weekday effect encourage investors to take risk hedging and arbitrage trade driving by investors' attitudes and psychology to risk based on prospect theory. To sum up, the findings of this article provide a new evidence against the Efficient Market Hypothesis (EMH) and contribute to the decision-making and improvement of market efficiency in the Indonesian Capital Market. 
[1] Birru, Justin, 2018, Day of the week and the cross-section of returns R, Journal of Financial Economics 130, 182-214.

[2] Boubaker, Sabri, Naceur Essaddam, Duc Khuong, and Samir Saadi, 2017, On the Robustness of Week-day effect to Error Distributional Assumption : International Evidence, Journal of International Financial Markets, Institutions \& Money 47, 114-130.

[3] Chiah, Mardy, and Angel Zhong, 2019, Day-of-the-week effect in anomaly returns : International evidence, Economics Letters 182, 90-93.

[4] Doyle, John R, and Catherine Chen, 2009, The wandering weekday effect in major stock markets, Journal of Banking \& Finance 33, 1388-1399.

[5] Fama, Eugene F., 1970, Efficient Capital Markets : A Review of Theory and Empirical Work, Journal of Finance 25, 28-30.

[6] Gibbons, Michael R, and Patrick Hess, 1981, Day of the Week Effects and Asset Returns, The Journal of Business 54, 579-596.

[7] Jeffrey, Jaffe, and Randolph Westerfield, 1985, The Week-End Effect in Common Stock Returns : The International Evidence, The Journal of Finance 40, 433-454.

[8] Kiymaz, Halil, and Hakan Berument, 2003, The day of the week effect on stock market volatility and volume : International evidence, Review of Financial Economics 12, 363-380.

[9] Mehdian, Seyed, and Mark J Perry, 2001, The Reversal of the Monday Effect : New Evidence from US Equity Markets, Journal of Business Finance and Accounting 28, 1043-1065.

[10] Solnik, Bruno, and Laurence Bousquet, 1990, Day-of-the-week effect on the Paris Bourse, Journal of Banking \& Finance 14, 461-468.

[11] Steeley, James M, 2001, A note on information seasonality and the disappearance of the weekend effect in the UK stock market, Journal of Banking \& Finance 25.

[12] Zhang, Chen, Po Yun, and Zulfiqar Ali Wagan, 2019, Study on the wandering weekday effect of the international carbon market based on trend moderation, .

[13] Zhang, Jilin, Yongzeng Lai, and Jianghong Lin, 2017, The day-of-the-Week effects of stock markets in different countries, Finance Research Letters 20, 47-62. 